\title{
Nano surface generation of grinding process using carbon nano tubes
}

\author{
$\mathrm{S} \mathrm{PRABHU}^{1, *}$ and B K VINAYAGAM ${ }^{2}$ \\ ${ }^{1}$ School of Mechanical Engineering, Sri Ramasamy Memorial (SRM) University, \\ Chennai 603203 \\ ${ }^{2}$ Department of Mechatronics Engineering, Sri Ramasamy Memorial (SRM) \\ University, Chennai 603203 \\ e-mail: Prabhume@yahoo.co.in; bkvei23@yahoo.com
}

MS received 12 August 2009; revised 2 March 2010; accepted 21 July 2010

\begin{abstract}
Nano surface finish has become an important parameter in the semiconductor, optical, electrical and mechanical industries. The materials used in these industries are classified as difficult to machine materials such as ceramics, glasses and silicon wafers. Machining of these materials up to nano accuracy is a great challenge in the manufacturing industry. Finishing of micro components such as micro-moulds, micro-lenses and micro-holes need different processing techniques. Conventional finishing methods used so far become almost impossible or cumbersome. In this paper, a nano material especially multi wall carbon nano tube is used in the machining process like grinding to improve the surface characteristics from micro to nano level.
\end{abstract}

Keywords. Nano surface finish; multi wall carbon nano tubes; grinding; atomic force microscope; surface roughness.

\section{Introduction}

Carbon nano tubes have been of great interest, both from a fundamental point of view and for future application. The most eye catching features of these structures are their mechanical, optical and chemical characteristics, which open a way to the machining application. CNTs have a tremendously high surface area, good electrical conductivity, and very importantly, their linear geometry makes their surface highly accessible to the electrolyte. This carbon nano tube is 100 times stronger than steel and weight is $1 / 6^{\text {th }}$ weight of steel. So this having high strength to weight ratio used in aerospace industry. Young's modulus of CNTs is over $1 \mathrm{TPa}$ vs $70 \mathrm{GPa}$ for aluminum, steel $2 \mathrm{Gpa}$ and $700 \mathrm{GPa}$ for C-fibre. The strength to weight ratio is 500 times greater than Aluminum (Sakas \& Simpson 2007). Maximum strain will be $10 \%$ much higher than any material. Thermal conductivity $3000 \mathrm{~W} / \mathrm{mK}$ in the axial direction with small values in the radial direction. Conductivity of CNTs is $109 \mathrm{~A} / \mathrm{cm}^{2}$ and Copper is $106 \mathrm{~A} / \mathrm{cm}^{2}$. CNTs having very high current carrying capacity, excellent field emitter and high aspect ratio.

*For correspondence 


\subsection{Previous work}

Mamalis et al (2004) proposed consolidated view of the synthesis, the properties and applications of carbon nanotubes, with the aim of drawing attention to useful available information and to enhancing interest in this new, highly advanced technological field for the researcher and the manufacturing engineer. Prabhu \& Vinayagam (2008) proposed nanosurface generation in grinding process using multi wall carbon nanotube with lubricant mixture to improve the surface finish of grinding process to nanolevel using good thermal conductivity of carbon nanotubes. Itoh \& Ohmori (1996) investigated the effect of finish ELID grinding on the flexural strength of silicon nitride specimens. Itoh et al (1998) proposed ELID-lap grinding being a method of constant pressure grinding, which utilizes an electrically conductive wheel and the ELID method. Sinha (2006) proposed his research with the deposition and tribological property characterizations of 1-2 nm thick nano-lubricants on solid surfaces for applications in data storage, micro-electro-mechanical systems and the newly emerging field of nanotechnology. Carbon nanotube nanofluids, is of special interests to researchers because of the novel properties of carbon nanotubes - extraordinary strength, unique electrical properties, and efficient conductors of heat. Carbon nanotubes (CNTs) are fullerene-related structures that consist of either a grapheme cylinder or a number of concentric cylinders (Wen \& Ding 2004). Choi et al (2001) has measured the effective thermal conductivity of SWCNTs dispersed in synthetic (poly- $\alpha$-olefin) oil and reported the enhancement up to a $150 \%$ in conductivity at approximately $1 \mathrm{vol} \% \mathrm{CNT}$, which is by far the highest thermal conductivity enhancement ever achieved in a liquid (Lockwood et al 2005). Solid lubricants are useful for conditions when conventional liquid lubricants are inadequate such as high temperature and extreme contact pressures. Their lubricating properties are attributed to a layered structure on the molecular level with weak bonding between layers. Such layers are able to slide relative to each other with minimal applied force, thus giving them their low friction properties. The considerable changes in the mixture of abrasive particles (Wong et al 1998) with Carbon nano tube when compared to the normal one. These results indicate that CNTs can be used as an additive in the lubricant. Guu (2005) proposed the surface morphology, surface roughness and micro-crack of AISI D2 tool steel machined by the electrical discharge machining (EDM) process were analysed by means of the atomic force microscopy (AFM) technique. Bin Shen (2008) proposed the nanofluid which is a new class of fluids engineered by dispersing nanometer-size solid particles in base fluids to increase heat transfer and tribological properties. This research studied the synthesis, characterization of nanofluids, and its application in minimum quantity lubrication (MQL) grinding. Xu et al (1996) investigated tribological properties of the two-phase lubricant of paraffin oil and diamond nanoparticles, and the results showed that, under boundary lubricating conditions, this kind of two-phase lubricant possesses excellent load-carrying capacity, anti-wear and friction-reduction properties. According to Verma et al (2007), MoS2 in its nanoparticulate form has exceptional tribological properties, which can reduce friction under extreme pressure conditions. Wu et al (2006) examined the tribological properties of lubricating oils with $\mathrm{CuO}, \mathrm{TiO}_{2}$ and diamond nanoparticles additives. The experimental results show that nanoparticles, especially $\mathrm{CuO}$, added to standard oils exhibit good friction-reduction and anti-wear properties.

\subsection{Multi-walled nanotubes (MWNT)}

Carbon nanotubes as shown in figure 1 have attracted the attention of many researchers since their discovery last decade. These carbon molecules are tiny tubes with diameters down to $0.4 \mathrm{~nm}$, while their lengths can grow up to a million times their diameter. Using their 


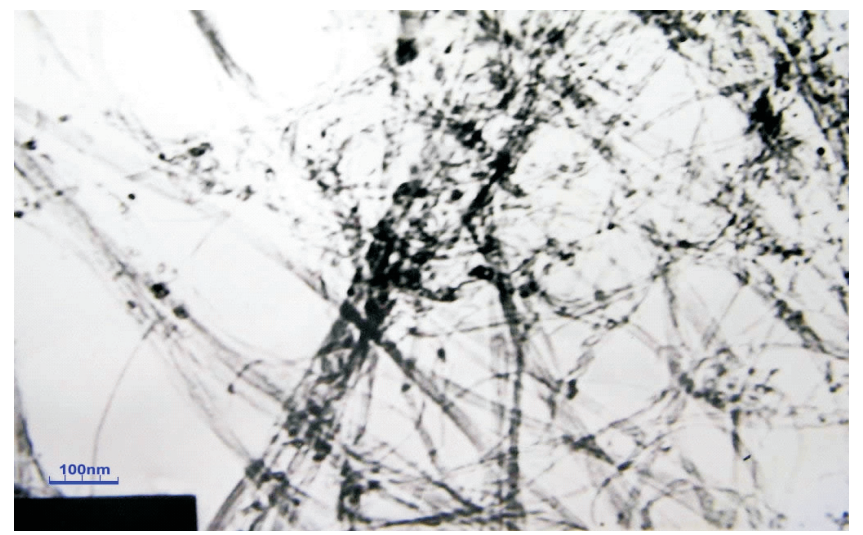

Figure 1. A TEM image of our MWCNTs $95 \mathrm{wt} \%<8 \mathrm{~nm}$ OD.

remarkable electrical properties, simple electronic logic circuits have been built. These structures are promising for the semiconductor industry which is leading the search for miniaturization. They are not only good conductors, but they also appear to be the material with the biggest specific stiffness, having half the density of aluminum. This gives a consolidated view of the synthesis, the properties and applications of carbon nanotubes, with the aim of drawing attention to useful available information and to enhancing interest in this new, highly advanced technological field for the researcher and the manufacturing engineer.

Carbon nanotubes which are related to graphite. The molecular structure of graphite resembles stacked, one-atom-thick sheets of chicken wire - a planar network of interconnected hexagonal rings of carbon atoms. In conventional graphite, the sheets of carbon are stacked on top of one another, allowing them to easily slide over each other. That is why graphite is not hard, but it feels greasy, and can be used as a lubricant. When graphene sheets are rolled into a cylinder and their edges joined, they form MWCNTs (table 1). The selected specification of multi wall carbon nanotube was purchased from Cheap Tubes Inc., USA.

\section{Proposed methodology}

\subsection{Selection of lubricant (mineral oil)}

A convenient lubricant should be selected. The commonly used oils are Biological oils which are suitable for applications in the food or pharmaceutical industry. Mineral oils are the most commonly used lubricants throughout industry. The next available economic grade is SAE20W40. This type of oil is widely used in large component manufacturing

Table 1. Specification of MWCNTs.

\begin{tabular}{ll}
\hline OD & $10 \mathrm{~nm}$ to $20 \mathrm{~nm}$ \\
Length & $10 \mu \mathrm{m}$ to $30 \mu \mathrm{m}$ \\
Purity & $>95 \mathrm{wt} \%$ \\
Ash & $<1.5 \mathrm{wt} \%$ \\
Specific Surface Area & $>233 \mathrm{~m}^{2} / \mathrm{g}$ \\
Electrical Conductivity & $>10^{-2} \mathrm{~S} / \mathrm{cm}$ \\
\hline
\end{tabular}


and automobile industries. Therefore SAE20W40 was selected as a lubricant for machining process.

\subsection{Mixing the lubricant with carbon nanotube}

A known quantity of the lubricant (SAE20W40) is mixed with Carbon nanotubes (Bin Shen 2008). 2 gm of MWCNT taken and mixed with $1000 \mathrm{ml}$ of the selected lubricants. Since the cost and availability of Carbon nanotube is a concern, this process has to be done with utmost care. The mixed lubricant has to be tested for finding the various properties such as Flash point, Fire point, Pour point, Kinematic viscosity, etc. (Bin Shen 2008).

\subsection{Testing the characteristics of lubricant with carbon nanotube}

After the lubricant is mixed with cabon nanotube, it has to be tested. This mixture of lubricant has to be checked for various properties such as Flash point, Fire point, Pour point, Kinematic viscosity, etc. Oil viscosity changes with temperature, shear rate, pressure and the thickness of the generated oil film is usually proportional to it. Flash point-temperature at which its vapor will ignite. Pour point-temperature at which the rate of flow will stop.

\subsection{Selection of work piece and machining process}

The work piece was chosen as AISI D2 tool steel which is very much used in molds and dies manufacturing Industry. A length of $1 \mathrm{~m}$ and $21 \mathrm{~mm}$ diameter of work piece was selected and cut the work piece in to small size with $10 \mathrm{~mm}$ width. The work piece is machined using lathe machine to reduce the diameter $20 \mathrm{~mm}$. The machined material was heated to $1030^{\circ} \mathrm{C}$ at a heating rate of $20^{\circ} \mathrm{C} / \mathrm{min}$ in muffle furnace. It was kept at $1030^{\circ} \mathrm{C}$ for one hour and then quenched. After quenching, the specimens were tempered at $520^{\circ} \mathrm{C}$ for two hours and then air cool.

\subsection{Hardening process}

The AISI D2 tool steel was first kept inside a muffle furnace. The temperature was set to $1030^{\circ} \mathrm{C}$ at $20^{\circ} \mathrm{C} / \mathrm{min}$ (Guu 2005). After reaching the desired temperature, the furnace was switched off and waited for one hour before the D2 tool steel was taken outside. Then oil quenching was done, after that Tempering process was done at a temperature of $520^{\circ} \mathrm{C}$ and then air cooled. The hardness of the work piece was found to be 57 HRC.

\subsection{AISI D2 tool steel}

AISI D2 tool steel is one of the carbon steels alloyed with Mo, Cr, and V, is widely used for various dies and cutters for its high strength and wear resistance. Table 2 lists the chemical composition (wt.\%) of the material AISI D2 tool steel and table 3 lists the mechanical properties of the AISI D2 tool steel.

Table 2. Chemical composition of the AISI D2 tool steel [wt.\%].

\begin{tabular}{lccccccccc}
\hline Elements & $\mathrm{C}$ & $\mathrm{Si}$ & $\mathrm{Mn}$ & $\mathrm{Mo}$ & $\mathrm{Cr}$ & $\mathrm{Ni}$ & $\mathrm{V}$ & $\mathrm{Co}$ & $\mathrm{Fe}$ \\
\hline Wt. $\%$ & 1.5 & 0.3 & 0.3 & 1.0 & 12.0 & 0.3 & 0.8 & 1.0 & Balance \\
\hline
\end{tabular}


Table 3. Mechanical properties of the AISI D2 tool steel at room temperature.

\begin{tabular}{lc}
\hline $0 \cdot 2 \%$ offset yield strength & $1532 \mathrm{MPa}$ \\
Tensile strength & $1736 \mathrm{MPa}$ \\
Hardness [HRC] & 57 \\
\hline
\end{tabular}

\subsection{Machining process}

Grinding process was chosen as a machining process and the surface grinding operation was performed on the work piece. This operation was performed on four samples. First sample was done without lubricant, second sample with water soluble oil, third sample with SAE20W40, and the fourth sample with SAE20W40 + MWCNT. The surface finish was obtained using AFM.

\subsection{Configuration of grinding system}

ELID grinding process: The basic ELID system consists of a power supply, a metal-bonded grinding wheel and an electrode. The electrode used could be $1 / 4$ or $1 / 6$ of the perimeter of the grinding wheel. Normally copper or graphite is selected as the electrode material. The gap between the electrode and the grinding wheel is adjusted up to 0.1 to $0.3 \mathrm{~mm}$. Proper gaps and coolant flow rate should be selected for efficient in-process dressing. Normally arcshaped electrodes are used in this type of elid and the wheel used is either straight or cup type. Figure 2 shows the mechanism of ELID grinding of metal-bonded diamond wheel. Murata et al (1985) introduced ELID for the application of abrasive cut-off of ceramics. Structural ceramics are highly difficult to grind owing to their hard and brittle nature.

\subsection{List of components used for grinding process}

The list of components used for grinding process includes: (i) abrasive wheel, (ii) metal bonded diamond wheel, (iii) copper electrode, (iv) carbon brushes, (v) dual regulated power supply, (vi) carbon nanotube, (vii) SAE20 oil.

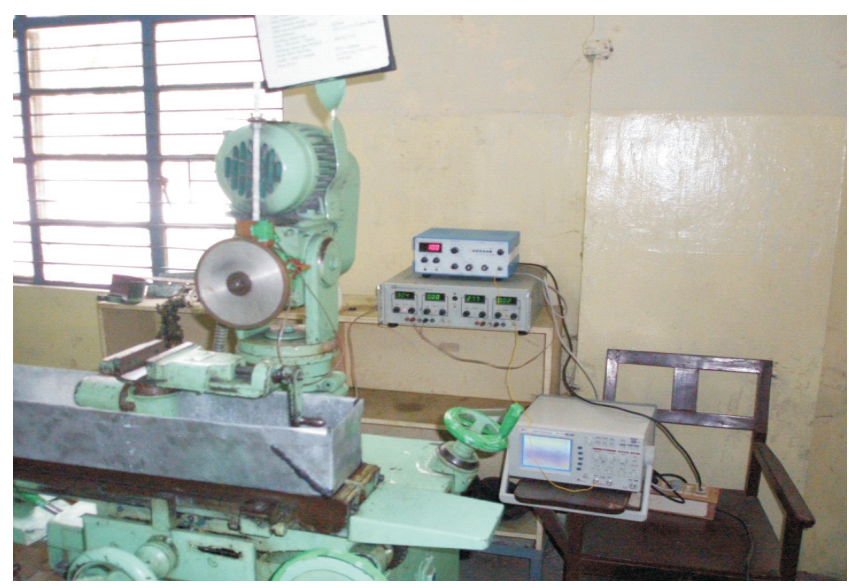

Figure 2. Experimental set-up. 
Table 4. Machine specification.

\begin{tabular}{ll}
\hline \multicolumn{1}{c}{ Grinding machine specification } \\
\hline PHI & Make \\
27 PTC & Model \\
$250 \mathrm{~mm}$ & Longitudinal travel \\
$175 \mathrm{~mm}$ & Cross travel \\
$10 \mathrm{~mm}$ & Width slot-T \\
$113 \times 500 \mathrm{~mm}$ & Table dimension \\
$305 \mathrm{~mm}$ & Admit between center \\
$262 \mathrm{~mm}$ & Table top to grinding wheel Distance (max.) \\
Bore $31.75 \times 13 \times 150 \mathrm{~mm}$ & Grinding wheel size \\
& (Diameter $\times$ thickness $\times$ bore) \\
Vitrified alumina & Grinding wheel \\
$528 \times 1 \times 30 \mathrm{~mm}$ & Nylon drive belt size \\
& (Width $\times$ thick $\times$ length) \\
$0.5 \mathrm{HP}, 3 \Phi, 50 \mathrm{~Hz}, 440 \mathrm{~V}, 280 \mathrm{rpm}$ & Main motor \\
\hline
\end{tabular}

\subsection{Conducting the experiment and comparing the results using surface roughness meter}

Each of the four samples was placed on the hinge of the surface roughness meter. The Ra values were found at four different places on each sample, their mean average value was taken as the final value. Since the surface might not be even at all places it was checked at four different places. Care should be taken while reading the values from the surface roughness meter.

\section{$2.11 A F M$}

An atomic force microscope (AFM) is a surface metrology instrument designed to study nanometer-scale features of very flat surfaces. For didactic and application purposes, it is useful to think of an AFM as a nanometer-scale stylus profilometer. Differences in the probe dimensions, the force loading mechanism, the probe-sample-position control system allow

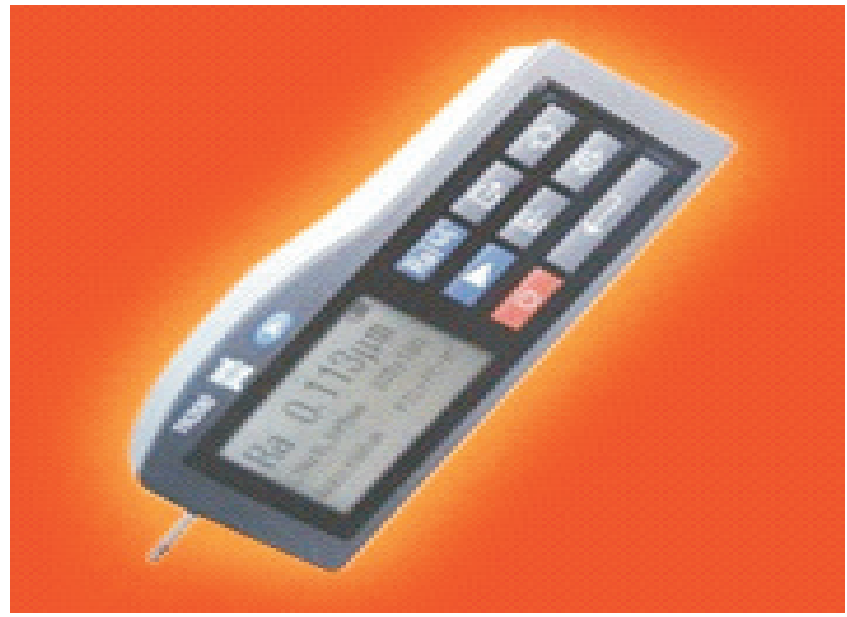

Figure 3. Surface roughness meter TR200. 
Table 5. Technical specification of TR 200.

\begin{tabular}{|c|c|}
\hline Roughness Parameters & $\begin{array}{l}\text { Ra, Rz, RY, Rq, Rt, Rp, Rmax, Rv, R3z, RS, RSm, RSk, Rmr } \\
\text { Primary profile (P) }\end{array}$ \\
\hline Assessed profiles & Roughness profile (B Rmr curve (material ration Mr.) \\
\hline Profile recording magnification & Vv: $200 x-20000 x$ Vh: 20x, 50x, 200x \\
\hline Measuring system & Metric imperial \\
\hline Display resolution & $0.001 \mu \mathrm{m} / 0.04 \mu \mathrm{inch}$ \\
\hline Display & LCD $128 \times 64$ dot-matrix, with back light \\
\hline Dimensions of LCD & $\begin{array}{l}50 \times 30 \mathrm{~mm} \text { screen pickup stylus position indicator battery } \\
\text { level indicator }\end{array}$ \\
\hline Display features & $\begin{array}{l}\text { Direct display of parameters and profile direct printing LCD } \\
\text { brightness adjustment auto-off after } 5 \text { minutes with auto- } \\
\text { store calibration through software }\end{array}$ \\
\hline Data output & RS 232, direct to printer TA $220 \mathrm{~S}$ or PC \\
\hline Range & $\begin{array}{l}\text { Ra, Rq: 0.01-40 } \mu \mathrm{m} \mathrm{Rz}, \mathrm{Ry}, \mathrm{Rp}, \mathrm{Rt}, \mathrm{R} 3 \mathrm{z}: 0 \cdot 02-160 \mu \mathrm{m} \text { Rsm, } \\
\text { RS: } 2-400 \mu \mathrm{m} \text { Rmr: } 1-100 \%\end{array}$ \\
\hline Cut-off length & $0.25 \mathrm{~mm} / 0.8 \mathrm{~mm} / 2.5 \mathrm{~mm}$ \\
\hline Evaluation length & $1-5$ cut-off (selectable) \\
\hline Tracing length & $(1-5$ cut-off $)+2$ cut-off \\
\hline Digital filter & RC, PC-RC Gauss D-P \\
\hline Pick-up & Standard model TS 100 , indicative, diamond tip radius $5 \mu \mathrm{m}$ \\
\hline
\end{tabular}

AFM better vertical and lateral resolutions. The first Atomic Force Microscope (AFM) was developed by Binnig, Gerber, and Quate at Stanford University by gluing a tiny shard of diamond onto one end of a tiny strip of gold foil. Currently AFM is the most common form of scanning probe microscopy.

Friction between two surfaces depends on the chemical and mechanical interaction between the surfaces. Changes in chemical composition giving rise to friction are measurable with the AFM (figure 4). The technique for measuring these forces is called lateral force, or frictional force microscopy. As the probe moves over a surface in the AFM, changes in the chemical composition of the surface can give rise to torsions of the cantilever on which the probe is mounted. The torsion of the cantilever is then proportional to the friction between the probe and the surface.

\section{Results and discussions}

Table 7 shows that the considerable changes in the mixture of SAE20W40 oil with multi wall carbon nanotube when compared to the SAE20W40 oil. These results indicate that carbon nanotubes can be used as an addictive in the lubricant. The carbon nanotube with lubricant mixture properties were tested and showed improved properties of lubricants.

Table 6. Classification of sample.

Sample 1 (with Lubricant)

Sample 2 (with water Soluble oil)

Sample 3 (with SAE20W-40)

Sample 4 (with SAE20W-40 + Multi wall carbon nano tube) 


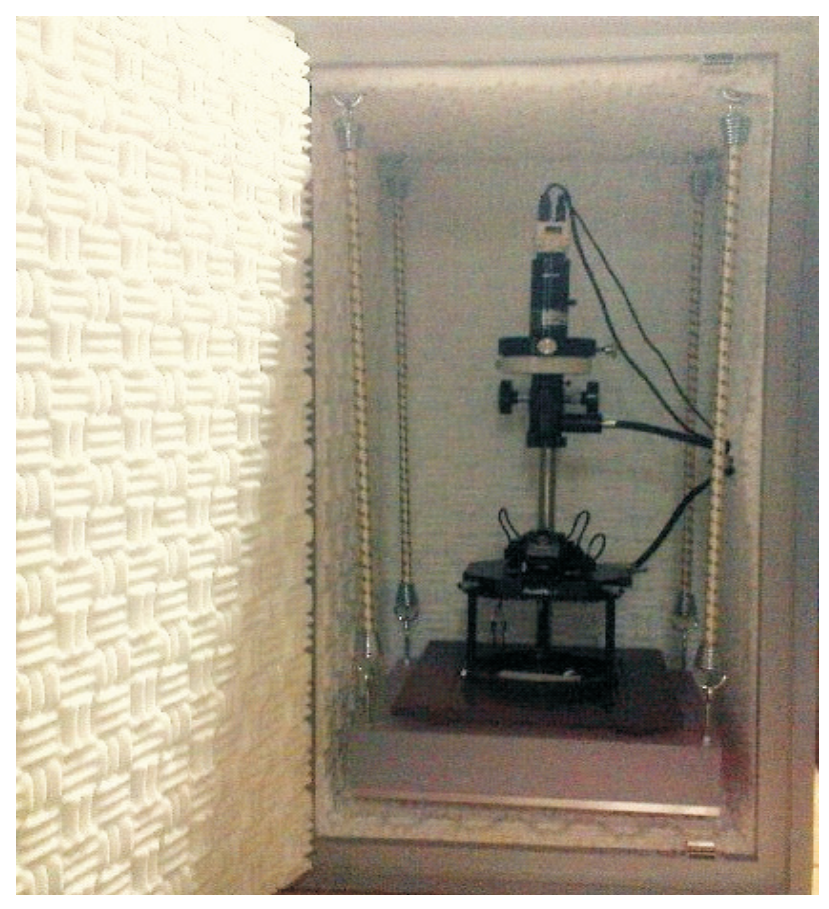

Figure 4. Atomic force microscope.

\subsection{Carbon nano tube mix with dielectric fluid}

Wear is the major cause of material wastage and loss of mechanical performance and any reduction in wear can result in considerable savings. Friction is a principal cause of wear and energy dissipation. Considerable savings can be made by improved friction control (Bin Shen 2008). It is estimated that one third of the world's energy resources in present use is needed to overcome friction in one form or another. Lubrication is an effective means of controlling wear and reducing friction.

\subsection{Lubrication}

Thin low shear strength layers of gas, liquid and solid are interposed between two surfaces in order to improve the smoothness of movement of one surface over another and to prevent damage. These layers of material separate contacting solid bodies and are usually very thin and often difficult to observe. In general, the thicknesses of these films range from

Table 7. Properties of lubricant with MWCNT.

\begin{tabular}{lcc}
\hline Properties & SAE20W-40 & SAE20W-40 + MWCNT \\
\hline Kinematic viscosity & 100 & $100 \cdot 1$ \\
Flash point & $215^{\circ} \mathrm{C}$ & $222^{\circ} \mathrm{C}$ \\
Fire point & $245^{\circ} \mathrm{C}$ & $234^{\circ} \mathrm{C}$ \\
Pour point & $-15^{\circ} \mathrm{C}$ & $-12^{\circ} \mathrm{C}$ \\
\hline
\end{tabular}


1 to $100 \mu \mathrm{m}$, if the film material consists of hard particles or merely flows against one body without providing support against another body then a form of wear, which sometimes can be very rapid, known as 'abrasive wear' occurs.

\subsection{Oil viscosity}

The parameter which plays a fundamental role in lubrication is oil viscosity. Different oils exhibit different viscosities. In addition, oil viscosity changes with temperature, shear rate and pressure and the thickness of the generated oil film is usually proportional to it.

\subsection{Viscosity temperature relationship}

The viscosity of lubricating oils is extremely sensitive to the operating temperature. With increasing temperature the viscosity of oils falls rapidly. In some cases the viscosity of oil can fall by about $80 \%$ with a temperature increase of $25^{\circ} \mathrm{C}$. From the engineering viewpoint it is important to know the viscosity value at the operating temperature since it determines the lubricant film thickness separating two surfaces (Çakir et al 2007).

\subsection{Flash point and fire point}

The 'flash point' of the lubricant is the temperature at which its vapour will ignite. In order to determine the flash point, the oil is heated at a standard pressure to a temperature which is just high enough to produce sufficient vapour to form an ignitable mixture with air which is the 'flash point'. The 'fire point' of oil is the temperature at which enough vapour is produced to sustain burning after ignition (Çakir et al 2007). By using this property the surface characteristics of grinding process was improved. The surface roughness values $(\mathrm{Ra})$ of the sample were tested by TR 200 surface roughness meter. The obtained value is given in table 8 .

\subsection{TR200 results}

These results (table 8) show that the surface finish can be improved by using the mixture of SAE20W-40 + MWCNT. The Ra values were found at four different places on each sample at macro level view figures 5-8, their mean average value was taken as the final value. Since the surface might not be even at all places it was checked at four different places. Where in sample 4 is a mixture of MWCNT and SAE20W40 resulted in a best surface finish with $\mathrm{Ra}$ value $0.057 \mu \mathrm{m}$. The carbon nano tube has a good thermal property which is utilized to absorb the heat developed during the machining process. This property influences to increase the surface finish.

Table 8. Surface roughness meter results.

\begin{tabular}{lc}
\hline Samples & Ra Values $(\mu \mathrm{m})$ \\
\hline Sample 1 (with no lubricant) & 0.251 \\
Sample 2 (with water soluble oil) & 0.137 \\
Sample 3 (with SAE20W-40) & 0.096 \\
Sample 4 (with SAE20W-40 + MWCNT) & 0.057 \\
\hline
\end{tabular}



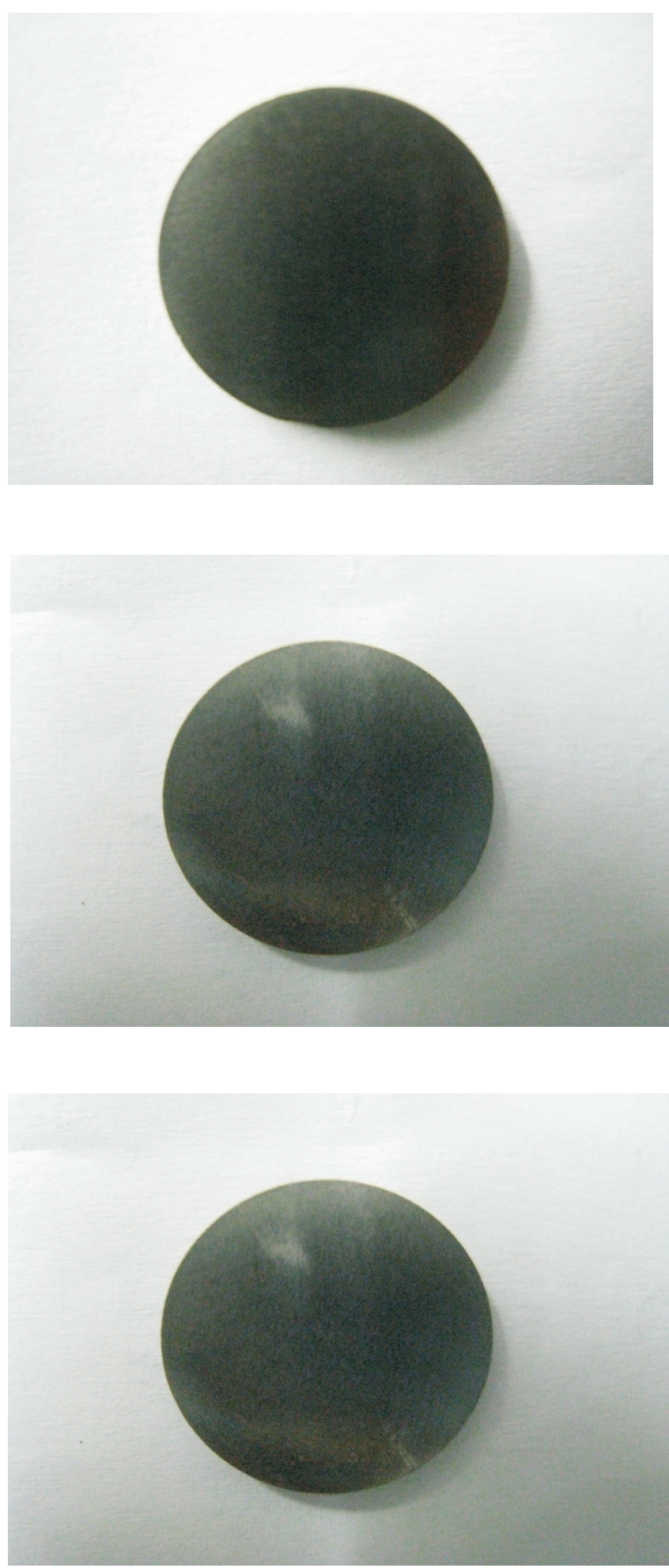

Figure 5. Sample 1 with lubricant.

Figure 6. Sample 2 with water soluble oil.

Figure 7. Samples 3 with SAE20W-40. 

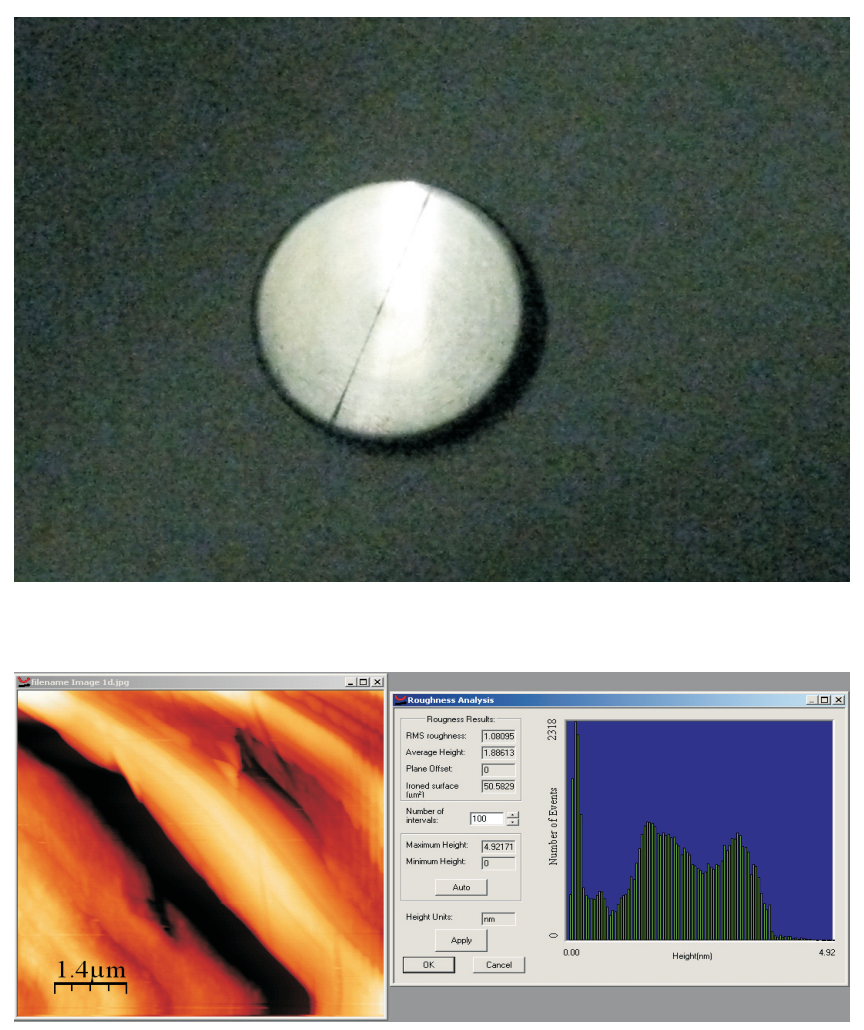

Figure 8. Samples 4 with SAE20W-40 and MWCNT.

Figure 9. Sample 1 without lubricant.

Table 9. Results of sample 1 (without lubricant).

\begin{tabular}{lr}
\hline RMS roughness & 1.09 \\
Average height & 1.88 \\
Maximum height & 4.92 \\
Minimum height & 0 \\
No. of intervals & 100 \\
\hline
\end{tabular}

Table 10. Results of sample 2 (with water soluble oil).

\begin{tabular}{lc}
\hline RMS roughness & $0 \cdot 83$ \\
Average height & $2 \cdot 81$ \\
Maximum height & $4 \cdot 63$ \\
Minimum height & 0 \\
No. of intervals & 100 \\
\hline
\end{tabular}


Table 11. Results of sample 3 (with SAE20W-40 oil).

\begin{tabular}{lc}
\hline RMS roughness & 0.678 \\
Average height & 1.233 \\
Maximum height & 3.711 \\
Minimum height & 0 \\
No. of intervals & 100 \\
\hline
\end{tabular}

Table 12. Results of sample 4 (with SAE20W-40 + MWCNT).

\begin{tabular}{lc}
\hline RMS roughness & 0.227 \\
Average height & -0.0111 \\
Maximum height & 0.90469 \\
Minimum height & -3.0310 \\
No. of intervals & 100
\end{tabular}
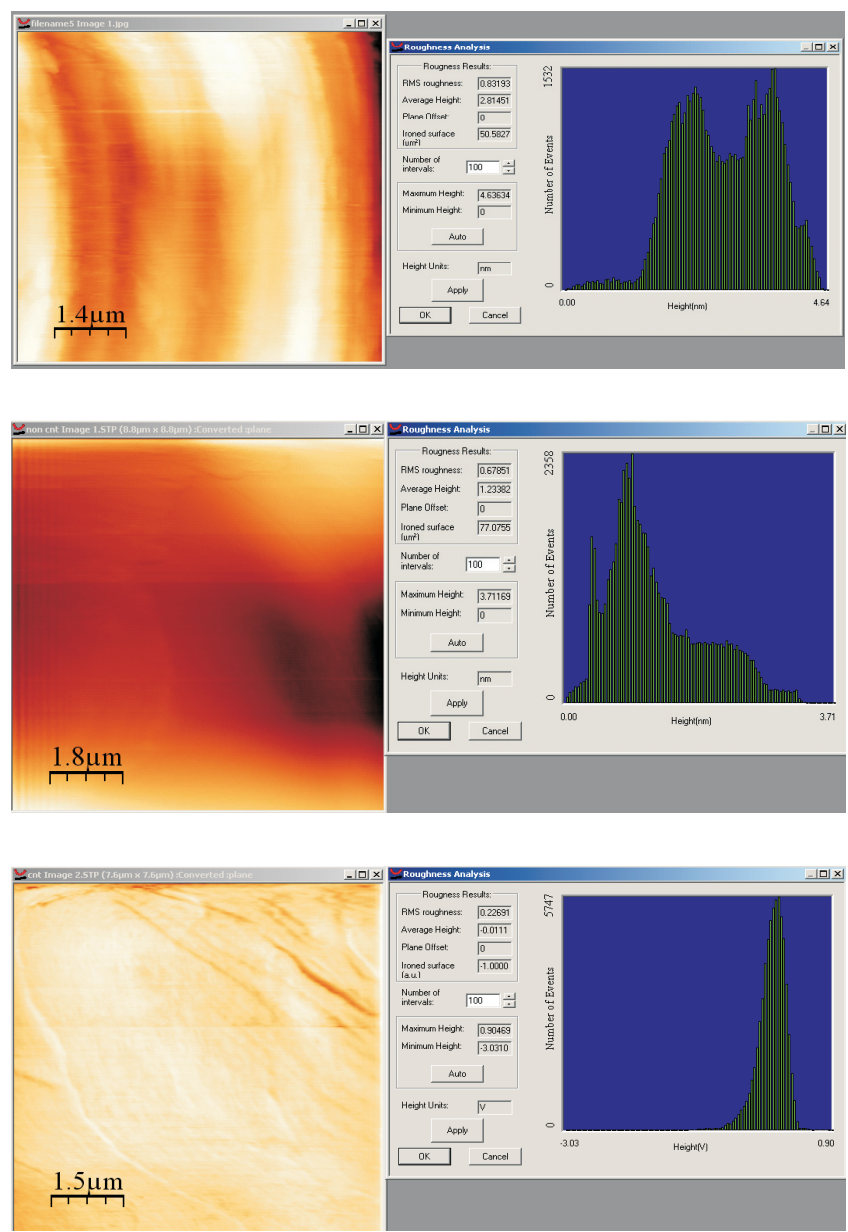

Figure 10. Sample 2 with water soluble oil.

Figure 11. AFM image and its results for $0 \mathrm{amps}$ without MWCNT.

Figure 12. AFM image and its results for 0 amps using MWCNT. 
Table 13. Comparisons of result of surface roughness.

\begin{tabular}{lcccc}
\hline & $\begin{array}{c}\text { Sample 1 } \\
\text { (with no } \\
\text { lubricant) }\end{array}$ & $\begin{array}{c}\text { Sample 2 } \\
\text { (with water } \\
\text { soluble oil) }\end{array}$ & $\begin{array}{c}\text { Sample 3 } \\
\text { (with SAE20W-40) }\end{array}$ & $\begin{array}{c}\text { Sample 4 } \\
\text { (with SAE20W- } \\
40+\text { MWCNT) }\end{array}$ \\
\hline Surface roughness in $\mu \mathrm{m}$ & 1.09 & 0.83 & 0.678 & 0.227 \\
\hline
\end{tabular}

\subsection{Surface roughness}

To determine the effect of the grinding process on the surface roughness of the tool steel, the surface profiles of the grinding specimens were measured by AFM. The average surface roughness $\mathrm{Ra}$, of the machined specimen was calculated from the AFM surface topographic data in a scanning area of $8 \mu \mathrm{m} \times 8 \mu \mathrm{m}$ and figures 10 and 11 show the measurement results. The surface roughness on the machined surface varied from 0.2 to $1.15 \mu \mathrm{m}$ for a scanning area of $8 \mu \mathrm{m} \times 8 \mu \mathrm{m}$. The parameters used are current 0 amps, pulse on duration $8 \mu \mathrm{s}$ and pulse off duration $7 \mu \mathrm{s}$. The roughness value obtained for the specimen using this parameter is $0.678 \mu \mathrm{m}$.

From table 13 it is clear that the specimens sparked using MWCNTs have better surface finish, reduced micro cracks and better surface morphology as compared with specimens sparked without CNTs.

\section{Conclusion}

The surface characteristics of AISI D2 tool steel material were analysed using Multi wall carbon nanotube in grinding process. The surface roughness were tested with and without multiwall carbon nano tube lubricant mixtures in grinding process using surface roughness meter TR200 and atomic force microscope (AFM). The result showed that using carbon nano tubes the surface characteristics were improved from micro level to nano level.

\section{References}

Bin Shen 2008 Minimum quantity lubrication grinding using nanofluids. The University of Michigan Çakir O, Yardimeden T, Ozben E, Kilickap 2007 Selection of cutting fluids in machining processes. $J$ Achievements in Materials and Manufacturing Eng. 25(2): Cheap Tubes Inc http://www.cheaptubesinc.com

Choi S U S, Zhang Z G, Yu W, Lockwood F E, Grulke E A 2001 Anomalous thermal conductivity enhancement in nanotube suspensions. Applied Phys. Lett. 79: 2252-2254

Guu Y H 2005 AFM surface imaging of AISI D2 tool steel machined by the EDM process. Applied Surface Science 242: 245-250

Itoh N, Ohmori H 1996 Grinding characteristics of hard and brittle materials by fine grain lapping wheels with ELID. J. Materials Process. Technol. 62(4): 315-320

Itoh N, Ohmori H, Kasai T, Karaki Doy T 1998 Finishing characteristics of brittle materials by ELIDlap grinding and metal-resin bonded wheels. Inter. J. Machine Tools Manufact. 38: 747-762

Lockwood F E, Zhang Z G, Forbus T R, Choi S U S, Yang Y, Grulke E A 2005 The current development on nanofluid research. SAE 2005 World Congress and Exhibition, Detroit, MI, USA

Mamalis A G, Vogtlander L O G, Markopoulos A 2004 Nanotechnology and nanostructured materials: Trends in carbon nanotubes. Precision Eng. 28: 16-30 
Murata R, Okano K, Tsutsumi C 1985 Grinding of structural ceramics. Milton C ShawGrinding Symposium PE16, 261-272

Prabhu S, Vinayagam B K 2008 Nano surface generation in grinding process using carbon nano tube with lubricant mixture. Inter. J. Nanotechnol. and Application 2(2-3): 149-160

Sakas D E, Simpson B A 2007 Operative neuro modulation: Neural networks surgery. (New York: Springer Wien) volume 2

Sinha Sujeet Kumar P 2006 Tribological studies of nano-lubricants March 31, National University of Singapore

Verma A, Jiang W, Abu-Safe H H, Malshe A P 2007 Tribological behaviour of the deagglomerated active inorganic nanoparticles for advanced lubrication. Tribology Transactions

Wen D, Ding Y 2004 Effective thermal conductivity of aqueous suspensions of carbon nanotubes (carbon nanotube nanofluids). J. Thermophysics and Heat Transfer 18(4): 481-485

Wong Y S, Lim L C, Rahuman I 1998 Near-mirror-finish phenomenon in EDM using powder-mixed dielectric.

J. Materials Processing Technol. 79: 30-40

Wu J H, Phillips B S, Jiang W, Sanders J H, Zabinski J S, Malshe A P 2006 Bio-inspired surface engineering and tribology of MoS2 overcoated CBN-TiN composite coating. Wear 261: 592-599

Xu T, Zhang J, Xu K 1996 The ball-bearing effect of diamond nanoparticles as an oil additive. Applied Physics 29: 2932-2937 